\title{
Virtual worlds players - consumers or citizens?
}

\author{
Edina Harbinja \\ University of Strathclyde, Glasgow, United Kingdom, e.harbinja@strath.ac.ukX
}

Published on 15 Oct 2014 | DOI: 10.14763/2014.4.329

\begin{abstract}
This article questions the preconceived notions that participants in virtual worlds are essentially consumers. Building on the existing scholarship around virtual worlds and notwithstanding the current character of virtual worlds, this paper explores aspects of End User Licence Agreements and notes the unfairness of their provisions, particularly the imbalance between user and developer interests governed by such contracts. It argues that the contracts cannot be regulated with consumer protection legislation, as interests such as property or intellectual property are beyond the scope of consumer protection regimes. Finally, recognising the phenomenon of constitutionalisation of virtual worlds, the article argues for stronger regulatory solutions in this domain, in order to strike a more appropriate balance between competing interests in virtual worlds.
\end{abstract}

Keywords: Virtual worlds, End User Licence Agreements, Consumer protection, Multi-User Dungeon (MUD), Massively multiplayer online role-playing game (MMOPG), Terms of service, Virtual asset

\section{Article information}

Received: 22 Jul 2014 Reviewed: 09 Sep 2014 Published: 15 Oct 2014

Licence: Creative Commons Attribution 3.0 Germany

Competing interests: The author has declared that no competing interests exist that have influenced the text.

URL: http://policyreview.info/articles/analysis/virtual-worlds-players-consumers-or-citizens

Citation: Harbinja, E. (2014). Virtual worlds players - consumers or citizens? Internet Policy Review, 3(4). https://doi.org/10.14763/2014.4.329

\section{INTRODUCTION}

The concept of virtual worlds (VWs) predates the emergence of the internet. Many authors report that the development of VWs has started with the text-based, offline role playing games, created on the basis of the different works of fiction, such as Tolkien's books and ideas of world building (Lastowka \& Hunter, 2006, pp. 17-18; Erlank, 2012, pp. 22-23). The first text-based interactive computer game appeared in 1970, The Colossal Cave Adventure (Lastowka \& Hunter, 2004, p. 17), with real-time interactive computer games called MUDs (Multi-User Dungeon) appearing by the end of the 1970s. These are first VWs. One early example of a MUD is MUD1, created by Richard Bartle and Roy Trubshaw in 1979, at Essex University. The most famous game in this group (text-based VWs) was LambdaMOO, created by Pavel Curtis in 1990 
(Lastowka \& Hunter, 2004, p. 20; Dibbell, 1998; Rex, n.d.).

Virtual worlds have continued to be a fascinating area for academic exploration. The scholarship analysing the social, economic, technological, legal aspects started in the late 1990s, focusing on the text-based VWs (Bartle, 1996). This continued throughout the 200os, discussing visually represented VWs and MMOPGs (massively multiplayer online role-playing games). The focus of the early literature was mainly on technical, philosophical and governance issues of MUDs. More substantive legal discussion started at the beginning of the 21st century, with seminal works on private law aspects of VWs (property and contracts). This academic analysis predominantly tackled the following issues: economies and taxation (Castronova, 2003; Lastowka \& Hunter, 2004), governance of VWs (Balkin, 2004; Crowley, 2006; Lastowka \& Hunter, 2004; Mayer-Schoenberger), property and IP in VWs (Cifrino, 2014; Erlank, 2012; Fairfield, 2005; Fairfield, 2007; Jankowich, 2006; Lastowka \& Hunter, 2004; Reynolds, 2003), contracts and consumer protection (Crowley, 2006; Jankowich, 2006; Riley, 2009); virtual crime (e.g. Lastowka \& Hunter, 2004; Lodder, 2013). This paper revisits the literature, notwithstanding the current character of VWs. It focuses on UK and EU policy issues, occasionally referring to the US for comparative purposes. The comparison is significant as both the majority of Western VWs case law originates from the US, and most commercially successful VW platforms are based there.

The article does not discuss the widely analysed concept of property in virtual worlds (virtual property). Rather, recognising the phenomenon of constitutionalisation of VWs, this paper argues for a more nuanced approach towards the recognition of in-world interests of users. It suggests that the EU and UK regulators should aim to create policy and legislative solutions, which would enable VWs users/citizens to take more control over their virtual assets and valuable VW accounts.

\section{CONCEPTUALISATION OF VIRTUAL WORLDS}

From an etymological perspective, VWs could be defined as states of human existence, which do not exist physically, are not real, but do appear to be real from the point of view of the programme or the user (The Oxford English Dictionary, 2013). From this definition, we could extract the most important features that define contemporary VWs as follows: computer moderated (users participate in VWs using computer and the internet); persistence (in the case of VWs, this element is relative and depends on the viability of a particular business model); environmental attributes (immersive and persuasive worlds, mimicking real world environment and physicality); interactivity (players interact with each other, e.g. participating in World of Warcraft quests); participation of multiple individuals (sometimes even millions, see data cited further in the article) (Erlank, 2012 pp. 47-57; Bell, 2008).

Developers use different business models for their VWs. Some VWs are closed, used for military or business simulations. Others are open, commercial worlds, where users can join for free, pay a monthly fee (like World of Warcraft), or operate on the freemium basis (like Second Life), where basic services are free, but value added services have a cost (see Fairfield, 2009 p. 53; Riley, 2009, p. 890).

The umbrella term for VWs is MMOPGs (the term widely used in the scholarship cited above, in addition to the versions such as MMOs, MMOGs), although the latter can be divided on the basis of their player community and structure: game worlds or social worlds. In game VWs 
(massively multiplayer online role-playing games - MMORPGs), players adopt a specific role and compete to achieve certain predefined goals (e.g. World of Warcraft, Eve Online). In the social or unstructured worlds, the goals are less strictly defined, and the emphasis is on social interaction with other players and with the environment (e.g. Second Life, IMVU). These VWs are not games per se, but are better considered platforms for social interaction, or so called "mirror worlds" (Kzero, 2014). The third kind of VWs is 'kids' worlds', where children are the targeted player demographic (e.g. Club Penguin) (Lastowka, 2010, p. 58).

We can also distinguish VWs by the technology employed to provide the user access to the world, for instance: client-based (e.g. World of Warcraft), and those where the players can join online (e.g. Second Life). Some games, including certain VWs (e.g. The Lord of the Rings Online, Dungeons \& Dragons Online, Everquest II, Diablo et al.) can also be accessed via intermediaries. The most prominent is a platform called Steam (Steam, 2013), "an entertainment platform", which distributes computer games and other software, from both independent and established software companies. It is also a communication, social networking of a sort and multiplayer platform, enabling a broader range of interactions between players akin to social networks. The further evolution of VWs includes innovative interaction hardware (e.g. Oculus Rift), bringing even more reality to these worlds (Kzero, 2014).

This paper focuses on two case studies: World of Warcraft and Second Life. The reason for choosing the US based VWs is that most of the successful Western VWs are hosted in the US (Edwards, 2011), contractual choice of law provisions ordinarily use US law, and the majority of common law cases have been resolved there (Fairfield, 2009, p. 430). Also, these examples are chosen due to their domination on the market, their large user base, their societal impact and 'cultural footprint' (Quinn, 2010, p. 760). Second Life is currently perceived as declining in popularity, but it is still worth mentioning as most of the existing case law involves this virtual world. Sporadic references might be made to other VWs and platforms, but the main analysis is based on these two virtual worlds.

For the purpose of this discussion, the term virtual assets (VAs) will be used to describe any item, object or asset found in VWs that is used or created by the players (e.g. avatar, weapon, land, house, clothes, furniture, and anything else that could be found in different VWs).

\section{MAIN FEATURES OF VIRTUAL WORLDS' END USER LICENCE AGREEMENTS}

Player obligations and rights, such as the allocation of ownership over virtual assets, intellectual property and different other rights in VWs are established through contracts between the players and the providers. VW contracts come in the form of click wrap licenses (End User Licence Agreements - EULAs; Terms of Service - ToS; rules of conduct and; different other policies) and the impact of these contracts are widely disputed. They often leave little or no freedom for the user and no other real choice apart from clicking "I agree" (Blizzard, 2014) or declining the contract, therefore refusing to take part in the game (Humphreys and de Zwart, 2012; de Zwart, 2010; Erlank, 2012, p. 99; Pistorius, 2004; Lemley, 2006). Usually, the game developers claim all the property and IP rights (Jankowich, 2006) associated with a VW. This, as seen further, is currently the most common model (Humphreys and de Zwart, 2012; Jankowich, 2006).

Blizzard, the World of Warcraft's developer, expressly excludes any property rights of users in 
assets created or traded in the game, as well as forbidding transfers of accounts (Blizzard, 2014, s. 4-5). There are certain MMOPGs that permit users to retain IP rights in their creations (Linden Lab, 2003). Second Life was the best known VW having used such a model (Vacca, 2008, p. 46). Linden Labs, developer of the virtual world Second Life, had promised to give users relatively extensive rights over content created by users therein (Linden Lab, 2010, title 7). However, these rights appear rather illusory, as Linden limits them to the game and refuses any liability and compensation in the case of damage, loss of this property (Erlank, 2012, p. 201). Nevertheless, by the way of insisting to regulate and limit virtual property, the developer seems to implicitly recognise the existence of the user interests in their VAs (Erlank, 2012, p. 112).

Since the contractual status of VAs in World of Warcraft is rather clear as noted above, it is interesting to look at Second Life's alleged liberal contractual provisions. Second Life appears to promise to grant and preserve a player's ownership of their virtual creations (Linden Lab, 2003). The current ToS grants users intellectual property rights in their creations, if any. However, it denies property rights in the in-game virtual currency, i.e., 'Linden dollars' (Linden Lab, 2014). Linden also denies any property rights in land that users can purchase in Second Life. The land represents a limited licence granted by Linden, and not a real property right (Linden Lab, 2014, s. 4.8.), and Linden disclaims any liability for modification, damages, loss of land (Linden Lab, 2014, part 9; Blizzard, 2014 part XVII). The motive behind this change in Linden's terms and outlook on player's ownership seems to be the case of Bragg, discussed later. Linden appears to have realised the risks the recognition of virtual property might create (Evans et al, Plaintiffs, $v$. Linden Research, Inc. et al, 2013).

Further, another pertinent issue is that the developers retain the right to unilaterally change or terminate the contract at any time (Linden lab, 2014, part 5; Blizzard, 2014, part XV). Conversely, they do grant themselves a non-exclusive licence in players' creations. Linden Lab, for example, has recently widened Second Life EULA in order to retain unlimited and irrevocable rights to use and exploit users' creations. This move left many players of Second Life embittered, wanting to leave this VW (Korolov, 2013).

\section{BRAGG V. LINDEN RESEARCH}

The most famous US virtual worlds court case is Bragg v. Linden Research, Inc. (2007). Marc Bragg sued Linden Research after they expelled him from the online community and reclaimed his virtual assets, confiscating his VAs of roughly \$2,00o in real-world money (Bragg v. Linden Research, Inc., 2007, p. 611), claiming that Bragg had violated their ToS by improperly buying the land at an auction. Second Life moved to compel arbitration according to the ToS. Bragg argued that the contractual terms between Bragg and Second Life were unconscionable because the agreement assumed too much power and was unreasonably biased against the user. The court confirmed that the terms of service were unconscionable in relation to the arbitration clause and knocked down the mandatory arbitration clause. The court also concluded that the terms left the plaintiff with no effective remedy (Hetcher, 2008, p. 836). The property claim was initially raised by Bragg, who had asserted that his in-game assets were in fact his property. The court, unfortunately, did not discuss this point, so virtual property still remains within the confines of academic debates.

More recently (2012), in Evans et al v. Linden Research, Inc. et al., the central issue was again fairness of the contract (provisions about suspension of accounts and users' compensation). A group of users claimed to own their VAs (Evans et al v. Linden Research, Inc. et al., 2012, Hr'g 
Tr. 27:12-28:11), and complained that they purchased virtual items and/or virtual land and later had their accounts unilaterally terminated or suspended by Linden. These players were not compensated for the value of the virtual land, items, and/or currency in their accounts. In addition, the plaintiffs claimed that Linden made false representations about ownership of virtual land and virtual items, and wrongfully confiscated these items from the class members they sought to represent (Evans et al v. Linden Research, Inc. et al., 2012, Hr'g Tr. 27:12-28:11). Linden disputed the claimed ownership, recognising only copyright in users' creations (Evans et al v. Linden Research, Inc. et al., 2012, Hr'g Tr. 37:7-10; 39:17-24; 53:15-24). Again, there was no decision with respect to ownership. The case was settled (Evans et al $v$. Linden Research, Inc. et al., 2012). It could be argued that this example illustrates Linden's attitude and concerns over ownership in VWs. Rather than proceeding with the case which could result in establishing some kind of property in virtual assets and thus endanger their EULA and their previous position, the developer prefers to compensate the users.

Even the 'liberal' providers and platforms seem to be replicating the EULAs presented above. For instance, Steam, a very successful platform (Wawro, 2014; Steam, 2014) is considered to be user-friendly, open-source to an extent and an alternative to the traditional business models. Valve, the owner of Steam, created a very restrictive EULA (Steam, 2014) for the content and games/VWs acquired via Steam, resembling very much those of the other VWs. Apart from the intellectual property rights (Steam, 2014, s.6), ownership by the players of their creations and virtual money, contained in their wallets (Steam, 2014, part C), is limited, non-transferable, with a wide licence taken by the provider, Valve Corporation (Steam, 2014, s. 6A). According to the recently published research on VWs (Kzero, 2014), other popular VWs amongst adults individuals with legal capacity, as required by the consumer protection and contracts law, thus subject to this analysis - are the social worlds IMVU (120 million users), Utherverse (22 million users), and sRepublic (6 million users). The analysis of these virtual worlds' ToSs and EULAs reveals, similar, mirroring, if not copying, of the previous EULAs, with the same issues around licensing, property, IP and liability. Research suggests that the provisions of these EULAs conflict with the user community norms and behaviours, thus lacking legitimacy and potentially resulting in undesirable outcomes when it comes to their enforcement (Suzor, 2010; Suzor and Woodford, 2013). However, notwithstanding these important findings, this article focuses predominantly on the EULAs and their unfairness and does not provide a more detailed account of the relevant community norms.

\section{CONSUMER PROTECTION AND VIRTUAL WORLDS}

The above analysis could hint, as many other authors do, to the fact that the contracts are prima facie unfair (Jankowich, 2006, p. 50). The logical remedy for this would be challenging their unfairness or unconscionable provisions in courts using consumer protection laws (Riley, 2009, p. 907).

At the EU level, the Directive 2011/83/EU of the European Parliament and of the Council of 25 October 2011 on consumer rights would potentially apply. This Directive, not yet implemented in the UK, encompasses the contracts regarding digital content, including games. Currently, at the UK level, The Unfair Terms in Consumer Contracts Regulations 1999 is also potentially applicable, if we recognise that when purchasing the licence to use software to enter the VW, users do act as consumers. According to this regulation, terms that would be potentially deemed as invalid include those limiting liability of the developer; those reserving the right to terminate or modify terms discretionary and without notice; arbitration clauses, etc. (The Unfair Terms in 
Consumer Contracts Regulations 1999, Sch. 2).

Both the UK and EU legislation address the issues such as provision of adequate information to consumers, rights of withdrawal, liability, delivery and passing of risk. This legislation, however, does not include the issues of property and IP rights, as the subject matter cannot be considered unfair and this is out of scope of this legislation (The Unfair Terms in Consumer Contracts Regulations 1999 S. 6. (2) or Rec. 51; Directive 2011/83/EU of the European Parliament and of the Council of 25 October 2011 on consumer rights; the Treaty on the Functioning of the European Union 2012, art. 345). This law could apply to the parts of the contracts regulating sale of the licence for using software. VAs in the form of players' creations would not fall within the definition of goods and services found in the consumer protection laws, as they are not goods or services sold by the developers. Alternatively, we could consider the UK Unfair Contract Terms Act 1977 (UCTA), which applies to all contracts, not just consumer contracts. Unfortunately, contracts dealing in any way with IP are beyond UCTA's scope, with it instead focusing on exclusion and limited contract clauses (Unfair Contract Terms Act 1977, Sch 1 s. 1). Similar, though much more limited protection can be found in California, mandated through Consumers Legal Remedies Act. This law prohibits inclusion of previously discussed unconscionable contract terms (California Civil Code $\S \S 1750$ et seq).

So far, VW contracts have not been challenged often in the UK and US courts. In the UK, there is no such case at the time of writing. In the US cases of Bragg and Evans, the courts did find certain provision of the contracts unfair (see previous section). Nevertheless, the courts' deliberations on the property rights have been quite accidental, in the context of discussing the main legal issues of the case. Therefore, we should not rely heavily on court cases to address the issue of a player's interest in VAs any time soon. Even if more cases do appear, the outcome, at least in the US might not be beneficial to the users (Randall, 2004; Quinn 2010).

In principle, the question of creating and/or recognising proprietary rights and interests in VWs is not an issue that can be regulated by contracts, but instead is one of the general laws of property/IP. In addition, an attempt of applying consumer protection law to virtual worlds' EULAs and allocation of property therein is contrary to the views of many authors mentioned in the subsequent section. This is because, VWs are not just games, and their inhabitants are not just users or players, but instead can be considered as active participants and citizens of the VWs, as indicated below.

\section{CONSTITUTIONALISATION OF VIRTUAL WORLDS}

Apart from allocating ownership over virtual assets, contracts have another important function: governance of the VWs.

Contracts are an effective and highly significant regulatory tool in VWs (Jankowich, 2006; Lastowka, 2010, Mayer-Schoenberger \& Crowley, 2006; Balkin, 2004), giving usually only a 'take it or leave it' option to users, as mentioned in the section above (Jankowich, 2006, p 6). Using mainly contracts, VW developers have 'omniscient and godlike' powers to control and regulate behaviours and interest of players, turning them into their subjects (Erlank, 2012, pp.75-76, 79; Jankowich, 2006). Jankowich coined a useful term for this regulation: 'EULAw', thereby characterising these agreements as "non-negotiated, infinitely modifiable, proprietorfriendly regulation" (Jankowich, 2006, p. 9). This is not a new phenomenon, though, as we have a similar situation for all standard-terms contracts. What makes these contracts different is the 
substance they attempt to regulate in their provision.

The rules of EULAs and ToS govern both legal and environmental aspects of VWs, such as etiquette, game rules, players' conflicts, in-game crimes, privacy policy, business policies, real world law of contracts, property, IP, dispute resolution (Jankowich, 2006, p 10; Linden Lab, 2014). Contracts are, therefore, hybrid contract/property documents, granting the users, in some cases, limited property/IP rights in their creations. They also exceed the principle of privity of contracts (binding nature between the parties only) (Fairfield, 2009, p. 451), or in civil law terms, in personam nature (Fairfield, 2009, p. 429). Therefore, these contracts create pseudo-property, pseudo-torts, pseudo-criminal and pseudo-constitutional systems. MayerSchönberger and Crowley rather sensibly characterise this phenomenon as constitutionalisation of VWs (Mayer-Schoenberger \& Crowley, 2006, pp. 1809-1810). Along the same line, Suzor notes the constitutional tensions in the regulation of VWs, arguing for reconceptualisation and evaluation of this framework, applying the rule of law principles to the private law regulation by EULAs (Suzor, 2010).

The providers also have a very strong mechanism of enforcement, through code (software, architecture), by restricting access to the world ex post. They have the abilities to change the worlds in any way they wish, to change their landscape, design functionalities and player's abilities (Balkin, 2004, p. 2049). In addition, one of the most effective methods of enforcement for the breach of EULAs provision is expulsion. Here, users incur significant costs when forced to leave the world, both in social (social capital, friends, built reputation, ties with one's avatar) and financial terms (monthly subscription fees and loss of all virtual property (MayerSchoenberger \& Crowley, 2006, pp. 1791-1792). They therefore rightly label VWs as "the most Lessigian of all spaces of online interaction" (Mayer-Schoenberger \& Crowley, 2006, p. 1791; Lessig, 2006).

Constitutionalisation could also be perceived as a consequence of VWs being 'places' on their own, with their own social interactions and culture, mimicking the real-world (Lastowka, 2010, p. 10, 46, 190). The social significance and features of VWs have been studied by the scholars from different disciplines, who embarked the task of explaining different social phenomena within VWs. Thus, for instance, VWs are places with rich cultures, with many players engaging in creation and art (e.g. films, called 'machinimas', created in the VWs and shared elsewhere later, e.g. on YouTube, see Lastowka, 2010, p. 190).VWs are also communities with an impressive social cohesion (see an empirical longitudinal study that tested social ties within the Everquest II, Shen, Monge \& Williams, 2011). They are used to explore and develop language skills (e.g. Tactical Language Project, developed at the University of Southern California Center for Research in Technology for Education, have taught language using virtual environments, see Fairfield, 2009, p. 1061); to engage in political activities (e.g. Second Life internal elections, or 2008 Hillary Clinton's Second Life campaign, see Wagner, 2004; Holloway, 2007; Crikey, 2007), for education (many notable education institutions, such as Harvard University or Yale, have had their Second Life profiles, as VWs are used to explore how users learn from play, see Oliver \& Carr, 2009), military (e.g. virtual environment There has designed a Virtual Baghdad project on commission for the Army, see Fairfield, 2009, p. 1060; Wertheim, 2004), medical (e.g. therapists use them to treat patients with Asperger's Syndrome, see Fairfield, 2009, p. 1059) and many other purposes.

The individual, social and economic characteristics of VW encourage many writers to claim that the worlds have "significance above and beyond their importance in the game context" (Chein, 2006, p. 1069). Therefore, as commentators observe "VWs are online places where games are 
usually played” (Lastowka, 2010, p. 119; Bartle, 2004). Some authors even suggest that players' avatars should have the rights online that correspond to human rights, since they are "the manifestation of actual people in an online medium" (Koster, 2000). VWs are qualitatively different from other kinds of games and real world social interaction, exactly by the unique interplay of their features, particularly due to the fact that these interactions happen in an environmentally peculiar, physical and 3D world (Erlank, 2012, pp. 51-52). Consequently, there is a much richer potential for creation in and building of VWs, in comparison with, for instance, social networks. The option and tools for creation are much more limited on social networks, stemming from their web-based interface, the lack of physicality. The ability to create using different tools and sharing these creations with a fellow user/player/citizen is one of the biggest motives for a player to participate in a certain VW (Lastowka, 2013). These features support the claim that further research is required on regulatory aspects of virtual worlds.

\section{CONCLUSION}

Clearly, the present forms of regulation of VWs through contracts and 'code' are not sustainable, due to aforementioned arbitrary, unfair and ad hoc characteristics. As such, they are inadequate tools for fair regulation of both the worlds as a whole, and the underlying social relationships between players/users/citizens and providers (Jankowich, 2006; Erlank, 2012, Fairfield, 2009; Lastowka, 2010, etc.). With regulation of VWs, these quasi-constitutions are unsuitable and there is a need for more certainty and accountability in relation to the player interests. Recognising the features of VWs, their distinct character and place-like qualities, it is necessary to provide for a more balanced legal and regulatory regime to protect the VW citizens and their interests (Lastowka, 2010, p. 17). This paper argued that the consumer protection legislation cannot address these issues, as the interests such as property or intellectual property are beyond the scope of this regime. It is also suggested that the problem could be addressed through legislation/regulation that would mandate recognition of the users' rights, acknowledging the rights and interests of the developer as well, perhaps through the form of property/quasiproperty rights. In this regard, there is a need for further research that would suggest some specific, nuanced regulatory and legal solutions, which would take a better account of the player interests in virtual worlds. 


\section{REFERENCES}

Balkin, J.M. (2004). Virtual Liberty: Freedom to Design and Freedom to Play in Virtual Worlds. Virginia Law Review, 90(8), 2043-2098.

Bartle, R. (1996). Hearts, clubs, diamonds, spades: Players who suit MUDs. Journal of Virtual Environments, 1(1). Retrieved from http://mud.co.uk/richard/hcds.htm

Bell, M.V. (2008). Toward a Definition of "Virtual Worlds". Journal of Virtual Worlds Research, 1(1). Retrieved from http://journals.tdl.org/jvwr/article/download/283/237JVWR

Blizzard. (2009). World of Warcraft - End User License Agreement. Retrieved from http://www.worldofwarcraft.com/legal/eula.html

Blizzard. (2014). World of Warcraft - End User License Agreement. Retrieved from: http://eu.blizzard.com/en-gb/company/legal/wow_tou.html or http://us.blizzard.com/en-us/company/legal/wow_tou.html

Bragg v. Linden Research, Inc., 487 F.Supp.2d 593 (E.D. Pa. 2007)

Carnival Cruise Lines, Inc. v. Shute, 499 U.S. 585, 600-01 (1991)

Castronova, E. (2003). On Virtual Economie. The International Journal of Computer Gaming Research, 3. Retrieved from http://www.gamestudies.org/0302/castronova/

Chein, A. (2006). A Practical Look at Virtual Property. St. John's Law Review, 50, 1059-1090.

Cifrino, C. (2014). Virtual Property, Virtual Rights: Why Contract Law, Not Property Law, Must Be the Governing Paradigm in the Law of Virtual Worlds. Boston College Law Review, 55, 235264 .

de Zwart, M. (2010). Contractual Communities: Effective Governance of Virtual Worlds. University of New South Wales Law Journal, 33(2), 605- 627.

Dibble, J. (1998). My Tiny Life: Crime and Passion in a Virtual World. New York, NY: Henry Holt.

Edwards, B. (2011, May 11). The 11 Most Influential Online Worlds of All Time. PCWorld. Retrieved from http://www.pcworld.com/article/22800o/influentialonlineworlds.html

Erlank, W. (2012). Property in Virtual Worlds. (Doctoral dissertation). Retrieved from http://ssrn.com/abstract=2216481

Evans et al v. Linden Research, Inc. et al., No. C-11-01078 DMR, United States District Court, N.D. California, November 20, 2012. Retrieved from:

http://law.justia.com/cases/federal/district-courts/california/candce/4:2011cvo1078/243627/1 07

Evans et al v. Linden Research, Inc. et al., No. C-11-01078 DMR. United States District Court, N.D. California. October 25, 2013. Retrieved from http://law.justia.com/cases/federal/district-courts/california/candce/4:2011cv01078/243627/1 28 
Fairfield, J. (2005). Virtual Property. Boston University Law Review, 85(4), 1047-1102.

Fairfield, J. (2008). Anti-Social Contracts: The Contractual Governance of Virtual Worlds. McGill Law Journal, 53, 427-476.

Fairfield, J. (2009). The End of the (Virtual) World. West Virginia Law Review, 112 (10), 53.

Hetcher, S. (2008). User-Generated Content and the Future of Copyright: Part Two -

Agreements Between Users and Mega-Sites. Santa Clara Computer \& High Technology Law Journal, 24, 829-867.

Holloway, D. (2007, July 11). Hillary Clinton flirts with Second Life. Crikey. Retrieved from http://www.crikey.com.au/2007/07/11/hillary-clinton-flirts-with-second-life/

Humphreys, S. \& de Zwart, M. (2012) Griefing, Massacres, Discrimination, and Art: The Limits of Overlapping Rule Sets in Online Games. UC Irvine Law Review, 2, 507-536

Jankowich, A. (2006). The Complex Web of Corporate Rule-Making in Virtual Worlds. Tulane Journal of Technology and Intellectual Property, 8, 1-60.

Korolov, M. (2013, September 30). Outrage grows over new Second Life terms. Hypergrid Business. Retrieved from

http://www.hypergridbusiness.com/2013/o9/outrage-grows-over-new-second-life-terms

Koster, R. (2000, August 27). Declaring the Rights of Players. Raph Koster's website. Retrieved from http://www.raphkoster.com/gaming/playerrights.shtml

Kutler, N. (2011). Protecting Your Online You: A New Approach to Handling Your Online Persona after Death. Berkeley Technology Law Journal, 26, 1641-1670.

Kzero Worldswide (2014). Consumer Virtual Reality: State of the Market Report. Retrieved from http://www.kzero.co.uk/blog/category/education-and-academia

Kzero Worldswide (2014). Radar Charts Q2 2014 VWs and MMOs shown by genre, average user age and status. Retrieved from http://www.kzero.co.uk/blog/category/education-and-academia

Kzero Worldswide (2014). Universe Charts Q2 2014: VWs/MMOs: Average User Age,

Registered Accounts \& Launch Date. Retrieved from

http://www.kzero.co.uk/blog/category/education-and-academia

Lastowka, F.G. \& Hunter D. (2004). The Laws of the Virtual Worlds. California Law Review, 92, pp. 1-74.

Lastowka, F.G. \& Hunter D. (2006). Virtual Worlds: A Primer. In J. M. Balkin \& B. S. Noveck (Eds.), The State Of Play: Laws, Games, And Virtual Worlds (pp. 13-28). New York, NY: NYU Press.

Lastowka, F. G. (2010). Virtual Justice: The New Laws of Online Worlds. New Haven, CT: Yale University Press.

Lastowka, F. G. (2013). The Player-Authors Project. Retrieved from

http://ssrn.com/abstract=2361758 or http://dx.doi.org/10.2139/ssrn.2361758 
Lemley, M.A. (2006). Terms of Use. Minnesota Law Review, 91, 459-483.

Lessig, L. (2006). Code, version 2.o. New York, NY: Basic Books.

Linden Lab. (2003). Second Life Residents to Own Digital Creations. (Press release) Retrieved from http://creativecommons.org/press-releases/entry/3906

Linden Lab. (2010). Second Life Terms of Service. Retrieved from

http://secondlife.com/corporate/tos.php?lang=en-US

Linden Lab. (2014). Second Life Terms of Service. Retrieved from http://lindenlab.com/tos

Lodder, A.R. (2013). Dutch Supreme Court 2012: Virtual Theft Ruling a One-Off or First in a Series? Journal of Virtual World Research, 6(3), 1-12

Mayer-Schoenberger, V. \& Crowley J.R. (2006). Napster's Second Life? - The Regulatory Challenges of Virtual Worlds. Northwestern University Law Review, 100, 1-12 1775-1826.

Oliver, M. \& Carr, D. (2009). Learning in virtual worlds: Using communities of practice to explain how people learn from play. British Journal of Educational Technology, 40, 444-457.

Pistorius, T. (2004). Click-Wrap and Web-Wrap Agreements. South African Mercantile Law Journal, 16, 568-576.

Quinn, P.J. (2010). A Click Too Far: The Difficulty In Using Adhesive American Law License Agreements To Govern Global VIRTUAL WORLDs. Wisconsin International Law Journal, 27 (4), 757-789.

Randall, S. (2004). Judicial Attitudes Toward Arbitration and the Resurgence of Unconscionability. Buffalo Law Review, 52, 185-224.

Rex, F. LambdaMOO: An Introduction. Retrieved from http://lambdamoo.rbriii.com/

Reynolds, R. (2003) "Hands off MY avatar! Issues with claims of virtual property and identity". Retrieved from http://www.ren-reynolds.com/downloads/HandsOffMYavatar.htm.

Riley, P. (2009). Litigating Second Life Land Disputes: A Consumer Protection Approach. Fordham Intellectual Property, Media and Entertainment Law Journal, 19(3), 877-923.

Shen, C., Monge P. \& Williams, D. (2011). The Evolving Virtual Relationships: A Longitudinal Analysis of Player Social Networks in a Large MMOG. Retrieved from http://dx.doi.org/10.2139/ssrn.1929908

STEAM. (2014). Steam \& Game Stats. Retrieved from http://store.steampowered.com/stats/

STEAM. (2014). Steam Subscriber Agreement. Retrieved from http://store.steampowered.com/subscriber_agreement/

Steinberg, A.B. (2009). For Sale--One Level 5 Barbarian for 94,80o Won: The International Effects of Virtual Property and the Legality of Its Ownership. Georgia Journal of International and Comparative Law, 37, 381-416.

Suzor, N. (2010). The role of the rule of law in virtual communities. Berkeley Technology Law 
Journal, 25, 1817-1886.

Suzor, N. \& Woodford, D. Evaluating Consent and Legitimacy amongst Shifting Community Norms: an EVE Online Case Study. Journal of Virtual World Research, 6(3), 1-14.

The Oxford English Dictionary (2014). Oxford University Press. Retrieved from http://www.oed.com/

Vacca, R. (2008). Viewing Virtual Property Ownership through the Lens of Innovation. Tennessee Law Review, 76, 33-64.

Wawro, A. (2014, January 15). Steam now has over 75 million active accounts. Gamasutra. Retrieved from

http://www.gamasutra.com/view/news/208667/Steam_now_has_over_75_million_active_ac counts.php

Wertheim, M (2004, July 6). Virtual Camp Trains Soldiers in Arabic, and More. The New York Times. Retrieved from

http://www.nytimes.com/2004/o7/06/science/virtual-camp-trains-soldiers-in-arabic-and-mor e.html?pagewanted=all\&src $=$ pm

Williams v. Walker-Thomas Furniture Co., 350 F.2d 445, 449 (D.C. Cir. 1965)

Zuckerberg, M. (2014, March 25) Facebook post. Retrieved from

https://www.facebook.com/zuck/posts/10101319050523971

\section{LEGISLATION}

California Civil Code $\S \S 1750$ et seq

Directive 2011/83/EU of the European Parliament and of the Council of 25 October 2011 on consumer rights O J L 304, 22/11/2011 P. 0064 - 0088

The Treaty on the Functioning of the European Union (Consolidated version 2012), OJ C 326, $26 / 10 / 2012$

The Unfair Terms in Consumer Contracts Regulations 1999 No. 2083

U.C.C. § 2-302 (amended 2003)

Unfair Contract Terms Act 1977 c. 50

\section{ACKNOWLEDGEMENT}

The author wishes to thank the Internet Policy Review reviewers and editors for their constructive criticism and suggestions. Thanks are also due to the author's friends Lachlan Urquhart and Emir Nukic for their useful comments and edits. 